\title{
Pre-, Intra- and Post-Operative Imaging of Cochlear Implants
}

\section{Prä-, intra- und postoperative Bildgebung bei Cochlea-Implantat}

Authors

Affiliations
T. J. Vogl', A. Tawfik ${ }^{2}$, A. Emam ${ }^{3}$, N. N. N. Naguib', A. Nour-Eldin ${ }^{4}$, I. Burck¹, T. Stöver ${ }^{5}$

Institute of Diagnostic and Interventional Radiology, University Hospital Frankfurt, Germany

Department of Diagnostic and Interventional Radiology, Mansoura University, Mansoura, Egypt

Department of Diagnostic and Interventional Radiology, University Hospital, Alexandria, Egypt

${ }^{4}$ Department of Radiology, University Hospital Cairo, Egypt

Department of Otolaryngology, University Hospital of Frankfurt, Germany

\author{
Key words \\ 0 ear \\ - MR imaging \\ - CT \\ anatomy \\ - schwannoma
}

received 21.7.2014

accepted 19.6.2015

Bibliography

Dol http://dx.doi.org/

$10.1055 / \mathrm{s}-0035-1553413$

Published online: 1.9.2015

Fortschr Röntgenstr 2015; 187:

980-989 ๑ Georg Thieme

Verlag KG Stuttgart · New York .

ISSN 1438-9029

\section{Correspondence \\ Prof. Thomas J. Vog}

Institut für Diagnostische und Interventionelle Radiologie,

J. W. Goethe-Universität

Frankfurt

Theodor-Stern Kai 7

60596 Frankfurt

Germany

Tel.: ++49/69/63017277

Fax: ++49/69/63017258

T.vogl@em.uni-frankfurt.de

\section{Zusammenfassung}

\section{$\nabla$}

Ziel dieser Übersichtsarbeit ist die Präsentation von bildgebenden Aspekten bei Patienten, die für eine mögliche Cochlea-Implantation infrage kommen sowie bei postchirurgischem Follow-up. Die Bildgebung spielt eine wichtige Rolle bezüglich der Informationen zu präinterventioneller Topografie, Variationen und möglichen Infektionen. Präoperative Bildgebung mittels DVT, CT, MRT oder CT und MRT zusammen ist notwendig für die Selektion der Patienten, für die Planung des chirurgischen Vorgehens und das Ausschließen von Kontraindikationen, wie z.B. das völlige Fehlen von Cochlea und dem Cochleanerv, oder Infektionen. Relative Kontraindikationen sind Variationen von Cochlea und Vestibulum. Intraoperative Bildgebung kann mittels Fluoroskopie, mobiler Radiografie oder DVT durchgeführt werden. Postoperative Bildgebung wird normalerweise mittels konventionellem Röntgen, DVT oder CT durchgeführt. Zusammenfassend spielt die radiologische Bildgebung eine wichtige Rolle in der prä- und postinterventionellen Phase bei Patienten, die für ein Cochlea-Implantat infrage kommen.

Kernaussagen:

- Intraoperatives Imaging: Röntgen, DVT

- Präoperatives Imaging: DVT, CT, MRT

- Postoperatives Imaging: X-Ray, DVT, CT

\section{Abstract \\ $\nabla$}

The purpose of this review is to present essential imaging aspects in patients who are candidates for a possible cochlear implant as well as in postsurgical follow-up. Imaging plays a major role in providing information on preinterventional topography, variations and possible infections. Preoperative imaging using DVT, CT, MRI or CT and MRI together is essential for candidate selection, planning of surgical approach and exclusion of contraindications like the complete absence of the cochlea or cochlear nerve, or infection. Relative contraindications are variations of the cochlea and vestibulum. Intraoperative imaging can be performed by fluoroscopy, mobile radiography or DVT. Postoperative imaging is regularly performed by conventional X-ray, DVT, or CT. In summary, radiological imaging has its essential role in the pre- and post-interventional period for patients who are candidates for cochlear implants.

Key Points:

- Intraoperative imaging: radiography, DVT

- Preoperative imaging: DVT, CT, MRI

- Postoperative imaging: X-ray, DVT, CT

Citation Format:

- Vogl TJ, Tawfik A, Emam A et al. Pre-, Intra- and Post-Operative Imaging of Cochlear Implants. Fortschr Röntgenstr 2015; 187: 980-989

\section{Introduction}

Cochlear implantation is a globally accepted treatment option for patients with severe to profound sensorineural hearing loss, in whom no or little improvement is provided by hearing aids. Cochlear implants enable such patients to perceive sound and understand speech as well as help to monitor their own speech and benefit intellectual development $[1,2]$. The main difference between cochlear implants and hearing aids is that the sound waves received by a cochlear implant are processed and converted into electrical impulse, rather than just amplified as with hearing aids [2]. A cochlear implant bypasses the hair cells in the organ of Corti and directly stimulates the cochlear nerve. Imaging plays a major role in cochlear implantation. Pre-operative imaging by CT, MRI or both modalities is essential for candidate selection and exclusion of contraindications, and may in- 
fluence the surgical approach. Intra-operative imaging is either routinely performed in many institutions or for difficult cases. Intra-operative imaging usually involves fluoroscopy or mobile radiography. However, advanced modalities such as flat-panel CT are becoming more available. Post-operative imaging by radiography, or more recently by $\mathrm{CT}$, is performed for confirmation of proper electrode placement or evaluation of suspected complications. In addition to its clinical importance, imaging is involved in cochlear implantation research studies and contributes to the development and evolution of cochlear implantation.

\section{Causes of Sensorineural Hearing Loss \\ $\nabla$}

Sensorineural hearing loss (SNHL) is defined as retrocochlear causes for hearing loss from the hair cells to the auditory cortex and occurs due to abnormalities in the inner ear, the vestibulocochlear nerve, or the central auditory pathway. The cause of SNHL may be congenital (hearing loss is usually present since birth) or acquired later in life.

Congenital SNHL may be further divided into hereditary or non-hereditary cases. About $30 \%$ of cases with hereditary SNHL present with another constellation of features that make up a distinctive clinical syndrome and are thus called "syndromic". On the other hand, most cases (about 70\%) with hereditary SNHL are non-syndromic [3]. To date, more than 110 chromosomal loci and 65 genes were identified as causes of non-syndromic SNHL [4].

Non-hereditary causes of congenital SNHL include prenatal infections (for example CMV and rubella), exposure to alcohol or ototoxic drugs (for example aminoglycosides and antineoplastic agents), prematurity and hypoxic-ischemic injury [3].

A less common cause for SNHL is otosclerosis, a progressive otodystrophy of the otic capsule, which can occur independently or together at the stapes footplate, and/or the pericochlear labyrinth, leading regularly to conductive hearing loss versus SNHL or in combination with mixed type hearing loss [5] ( $\bullet$ Fig. 1).

Acquired forms of SNHL present in late childhood or adulthood, and include trauma, inner ear infections and autoimmune diseases, or cerebellopontine angle/internal auditory canal tumors [6]. Other causes include noise-induced SNHL and presbycusis (॰ Fig. 2).

Clinical studies have demonstrated acceptable results of $\mathrm{CI}$ in individuals with several forms of hereditary SNHL, especially when implantation is performed at a very young age, provided that the cochlear nerve is present. The presence of multiple disabilities in syndromic patients is no longer a contraindication for $\mathrm{CI}$ [7]. Congenital CMV infection and most non-hereditary causes of SNHL do not represent a contraindication for $\mathrm{CI}$. Patients with acquired forms of bilateral SNHL are generally considered candidates for $\mathrm{CI}$.
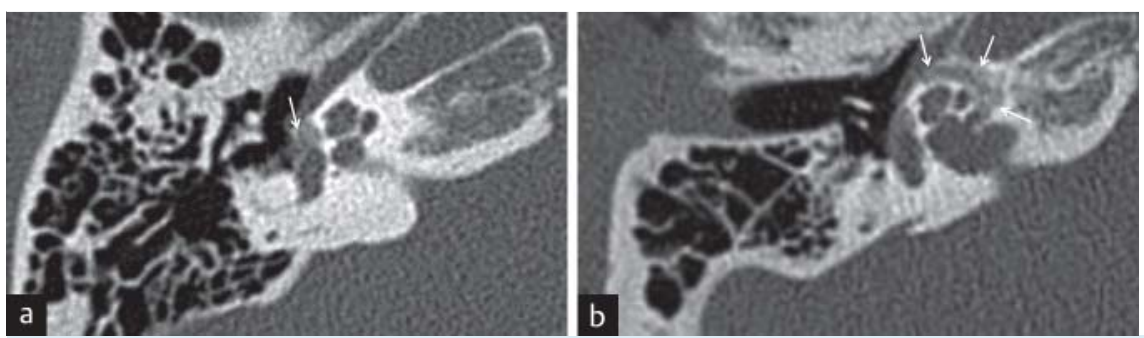

Fig. 1 MDCT in a 26-year-old patient with mixed hearing loss. a Right axial CT scan in a young adult with progressive conductive hearing loss demonstrates typical lytic otospongiotic plaque of fenestral otosclerosis anterior to the oval window (white arrow). b Magnified right axial CT scan in the same patient with hypodensity surrounding the cochlea appearing as a "halo" (white arrows).
Abb. 1 MDCT bei einem 26-jährigen Patienten mit gemischtem Hörverlust. a CT axial rechts bei einem jungen Erwachsenen mit progressivem Schalleitungshörverlust zeigt typisch lytisch otospongiotische Plaques begleitet von bilateraler fenestraler Otosklerose anterior zum ovalen Fenster (weißer Pfeil). b Vergrößerte rechte axiale CT-Aufnahme mit einer die Cochlea umschließenden Hypodensität, die als „Halo“ erscheint (weiße Pfeile).
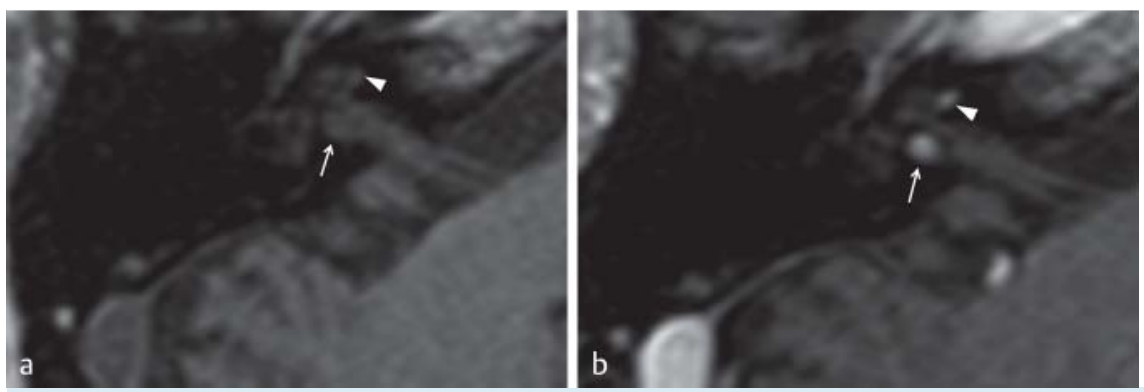

Fig. 2 Intralabyrinthine schwannoma. a Axial T1w MR image presenting the region of the right inner ear with marked right basal turn of the cochlea (white arrowhead) and IAC close to the vestibule (white arrow). b After contrast medium application, enhancing masses present as intralabyrinthine schwannoma of the cochlear nerve (white arrowhead) and a tumor mass in IAC (white arrow).
Abb. 2 Intralabyrinthäres Schwannom. a Axiale T1-gewichtete MR-Tomografie mit Darstellung des rechten Innenohres mit Markierung der Region der rechten basalen Windung (weiße Pfeilspitze) sowie der Region des inneren Gehörganges nahe dem Vestibulum (weißer Pfeil). b Nach Kontrastmittelapplikation zeigen sich kontrastangereicherte Raumforderungen als intralabyrinthines Schwannom des Nervus cochlearis (weiße Pfeilspitze) und ein Tumor im inneren Gehörgang (weißer Pfeil). 


\section{Cochlear Implants}

$\nabla$

A cochlear implant $(\mathrm{CI})$ consists of external and internal parts. A microphone is worn behind the ear to collect sound waves, which are processed by an attached speech processor. The encoded waves are sent through the skin into the internally placed receiver or stimulator by a transmitter. The waves are then transmitted to the electrode array that is surgically inserted into the cochlea in close proximity to the auditory nerve [2].

Currently, there are 4 cochlear implant devices worldwide: Clarion provided by Advanced Bionics (USA), Nucleus provided by Cochlear Limited (Australia), Combi $40+$ provided by MED-EL (Austria) and Digisonic provided by Neurelec (France). The 4 devices are approved for use in Europe and other regions in the world, while only the first 3 devices are currently approved for use in the United States. There is no universal agreement about the superiority of any of these devices, but there are differences in speech encoding, number of electrodes, materials used, design and other technical innovations. The choice of a certain device will usually depend on the availability and familiarity with the device, cosmetic and durability factors, as well as certain anatomic patient factors.

The standard surgical technique is mastoidectomy and posterior tympanotomy $[2,5]$. After mastoidectomy, major landmarks are identified including incus, horizontal semicircular canal, facial nerve, and chorda tympani. A posterior tympanotomy is then performed to gain access into the middle ear via the facial recess, bounded by the facial nerve posteriorly and the chorda tympani anteriorly. The round window (RW) of the cochlea is then identified and the cochlea entered either via the RW or via a separate cochleostomy to allow insertion of the electrode array $[8,9]$.

An alternative less invasive surgical approach, the suprameatal approach, has been proposed. Instead of mastoidectomy, this approach gains access to the middle ear through a retro-auricular tympanotomy flap. A narrow tunnel is drilled in the suprameatal region in order to insert the electrodes into the cochlea. This technique avoids damage to the facial nerve and chorda tympani $[10,11]$

\section{Indications for Cochlear Implantation}

$\nabla$

As awareness and experience with $\mathrm{CI}$ continue to increase, indications for $\mathrm{CI}$ continue to expand. Indications have to be differentiated for children and adults. $\mathrm{CI}$ is generally indicated for patients who are expected to attain better hearing and speech understanding with $\mathrm{CI}$ than with hearing aids. According to the age of onset of hearing loss, 3 terms are used for description. Pre-lingual hearing loss is present at birth or within the first 2 years of life; peri-lingual hearing loss occurs between the age of 2 and 4; and post-lingual hearing loss starts after the age of 4 . Pre-lingual children with hearing loss should be treated as soon as possible, preferably within the first year of life or as soon as the diagnosis and indications of $\mathrm{CI}$ are verified. Peri-lingual children should also be treated without delay. Post-lingual children or adults do not require treatment urgently, yet the best results are expected [1]. Immediate indications for $\mathrm{CI}$ implantation are essential in the case of meningitis and cochlear obliteration.

The classic candidates are patients with bilateral severe hearing loss of cochlear origin. Newer indications include patients with unilateral deafness associated with severe tinnitus, and CI may be considered as one of the most successful treatment options for severe disabling tinnitus in selected patients [7]. Another recent indication for $\mathrm{CI}$ is hearing preservation in patients with significant low frequency residual hearing [7]. For this purpose, a new hybrid stimulation system was developed that consists of a short $\mathrm{CI}$ electrode to restore high frequency loss and a conventional hearing aid to stimulate residual low frequency hearing.

\section{Contraindications for Cochlear Implantation $\nabla$}

Absolute contraindications for $\mathrm{CI}$ include the absence of the cochlea or the cochlear nerve $[1,2]$. The newer literature documents data on improved results documented in patients with cochlear aplasia using CI $[12,13]$. Other inner ear malformations complicate surgical implantation but are not regarded as contraindications. Infections of the middle ear must be controlled first before surgery. Other relative contraindications include poor general condition and treatment-resistant epilepsy [1].

\section{Pre-Operative Imaging \\ $\nabla$}

Pre-operative imaging with high-resolution computed tomography (CT) and magnetic resonance imaging (MRI) aims at the evaluation of congenital anomalies and other lesions of the cochlea, surgical planning and evaluation of the cochlear nerve [14].

CT is the best modality for the assessment of bone anatomy and bony anomalies. In addition, the width of the cochlear aperture and of the internal auditory canal can serve as an indirect indicator of possible hypoplasia of the cochlear nerve through assessment via CT. Its cost is lower and the scanning time is much shorter compared to MRI, with less need for anesthesia in children. CT also allows the simultaneous delineation of the skull base and middle and inner ear anomalies $[15,16]$. MRI, on the other hand, provides better soft tissue contrast and is the modality of choice for imaging of the cochlear nerve. The lack of ionizing radiation is a major advantage especially in children $[3,16]$. There is a trend towards performing MRI rather than CT for preoperative assessment before cochlear implantation, encouraged by the technical advances in MRI. High-resolution MRI can depict the morphology of the fluid-filled inner ear and the nerves in the internal auditory canal, which are the minimum requirements for surgical indication [14]. In 2014 Giesemann et al. also presented results of improved imaging of cochlear nerve hypoplasia especially with respect to the problem of the visualization of an absence of the cochlear nerve [17]. Moreover, the MRI examination may be extended to include the brain together with the temporal bone to examine the central auditory pathway and detect any associated parenchymal abnormalities [16]. CMV is often detected, and sometimes polymicrogyria, hindbrain malformation or rare disorders like Hurler's disease [18]. Even in institutions where MRI is the preferred modality of choice for the evaluation of SNHL, complementary CT will also be performed for cases with cochlear anomalies or suspected anomalous course of the facial nerve or with concomitant conductive hearing loss [3]. CT as well as MRI provide specific information and may be considered as complementary to one another. The combined use of both modalities for preoperative imaging before cochlear implantation may identify more relevant abnormalities, which would not be detected using only a single modality [15]. 


\section{Technique of CT Imaging}

Modern multi-detector CT scanners are capable of providing high-resolution $\mathrm{CT}$ of the temporal bone with sub-millimetric thin sections. Isotropic imaging with section collimation from 0.3 to $0.6 \mathrm{~mm}$ is now available with true isotropic spatial resolution. Images may be acquired in the axial plane and then readily reconstructed into coronal images, thus reducing the radiation dose and the examination time compared to direct axial and coronal imaging [19]. Several oblique reformats were studied and proven clinically useful, for example reformats to detect semicircular canal dehiscence with sagittal long-axis and $90^{\circ}$ orthogonal short-axis views especially in the superior and posterior semicircular canal [20]. Isotropic imaging using a high-resolution bone algorithm allows reconstruction of three-dimensional images of high quality that may be useful for surgical planning [21].

Measures to reduce the radiation exposure while preserving thin collimation imaging were suggested including lowering the tube current or using the single-shot technique available with the latest generation scanners which allows imaging of the whole temporal bone volume in a single tube rotation [22]. The radiation dose to the lens can be reduced by modifying the plane of acquisition of axial images, then reconstructing images in the routine planes [22].

\section{Flat-Panel CT}

$\nabla$

Advances in detector technology led to the development of flatpanel detectors, which were originally designed for conventional radiography, but were later implemented in CT technology. Flatpanel detectors enable direct and repeatable conversion of X-ray energy into digital signals with higher spatial resolution and dynamic range than older image intensifiers.

C-arm fluoroscopy systems equipped with flat detectors were recently developed. Those systems enabled projections obtained over an angular range of more than $180^{\circ}$, generating volume data sets, which could be reconstructed into CT-like images [23]. For imaging of the temporal bone, the volume data set could be acquired with isometric voxels of sub-millimetric size (as thin as $0.3 \mathrm{~mm}$ ). The isometric nature offers the possibility of excellent multi-planar, curved and $3 \mathrm{D}$ reformats such as volume rendering, surface-shaded display and maximum intensity projection techniques.

The main advantage of flat-panel CT in temporal bone imaging is the higher spatial resolution of up to $150 \mu \mathrm{m}$, which is higher than that of conventional MSCT. This allows improved overall image quality and reduced partial volume averaging, with marked improvement in delineation of small and thin bony structures, such as the superstructure of the stapes. Other advantages of flat-panel CT include less metallic artifacts and lower radiation exposure than conventional MSCT. The main limitation of flatpanel CT is the lower soft tissue contrast in comparison to MSCT $[14,24]$. Digital volume tomography is increasingly used in the intra-operative and post-operative evaluation of $\mathrm{CI}$ procedures.

\section{Cone Beam CT}

$\nabla$

Cone beam CT is another relatively recent innovation in CT technology. It is based on conical rather than fan-beam geometry of the X-ray between the source and detector, and most mo- dern cone beam CT scanners are also equipped with flat-panel detectors.

The low cost and compact size of cone beam CT compared to conventional CT scanners have enabled their office-based use in dedicated dental as well as head and neck imaging. Cone beam CT may be used for the intra-operative guidance or post-procedural evaluation of CI. Similar to flat-panel CT, the main disadvantage of cone beam CT scanners is the lower soft tissue resolution compared to conventional MSCT, which limits the ability to detect small changes in the attenuation of soft tissue [25].

\section{Technique of MR Imaging}

$\nabla$

Technical advances in MRI including higher field strength, stronger gradients and coil technology have stimulated the development of several imaging sequences that can be used for temporal bone imaging. Imaging of the temporal bone is best performed with T2-weighted sequences, which provide optimum contrast between neural tissue and cerebrospinal fluid as well as between fluid within the membranous labyrinth and background [16].

High resolution with dedicated sequences for stationary fluids and using the thinnest possible sections is optimal for temporal bone imaging. This can be achieved by $2 \mathrm{D}$ acquisition, but $3 \mathrm{D}$ sequences generally offer thinner sections and allow optimum multi-planar reformatting and $3 \mathrm{D}$ rendering of the cochlea [26]. Both highly T2-weighted fast-spin echo and fast gradient-recalled echo sequences may be used [27]. One example of spin-echo sequences is the $3 \mathrm{D}$ fast recovery fast spin-echo pulse sequence which makes use of a negative $90^{\circ}$ pulse at the end of the echo train to return the transverse magnetization of CSF to the longitudinal axis. This enables heavy T2-weighting with bright fluid signal intensity in a shorter repetition time [27]. On the other hand, the most commonly used gradient-recalled echo sequence is the $3 \mathrm{D}$ constructive interference in steady state (CISS) or fast imaging employing steady-state acquisition (FIESTA), where both longitudinal and transverse magnetizations are kept constant (steady-state) by using a repetition time that is shorter than the T2 relaxation time of tissue [28]. Advantages of the CISS sequence include high signal-to-noise ratio because tissues with a long T2 relaxation time acquire an additional signal. There is an excellent contrast between the neural structures and CSF. Oblique sagittal images are obtained in planes perpendicular to the course of the seventh and eighth nerves in the internal auditory canal. Those images delineate the four nerves in the IAC: facial, cochlear, superior and inferior vestibular nerves [29].

The use of intravenous contrast is not mandatory, especially in children with congenital hearing loss. Contrast administration is reserved for children and adults with suspected retrocochlear neoplasm or inner ear infection/inflammation. In addition, most authors recommend additional imaging of the whole brain using routine sequences including spin echo T1- and T2-weighted and FLAIR sequences [3].

\section{Pre-Operative Imaging Findings}

Pre-operative CT provides invaluable information about relevant structures. The cochlea should be evaluated for malformations and patency; the width of the internal auditory canal should be noted; the round window evaluated for patency; the cochlear 
and vestibular aqueducts for width; the carotid canal and jugular bulb for course variation or dehiscence; the facial nerve evaluated for its course and bony covering; the mastoid for degree of pneumatization and presence of mastoiditis; and the middle ear for the presence of otitis or cholestaeatoma [30].

Pre-operative MRI is the method of choice for the detection of hypoplasia and the absence of the cochlear nerve [16]. MRI is also superior to CT in the detection of fibrous obliteration of the cochlea where the high signal fluid characteristic of a patent cochlear lumen is replaced by the low signal of fibrous tissue. CT, however, is preferable for the differentiation between fibrous obliteration and cochlear ossification which complicates $\mathrm{CI}$ insertion [31]. In addition, MRI may reveal an occult retrocochlear neoplasm or an associated cerebral lesion.

\section{Inner Ear Malformations}

$\nabla$

Congenital malformations of the inner ear that are radiologically visible may be encountered in only about $20 \%$ of patients with congenital SNHL [31]. Malformations that involve only the membranous labyrinth are not detected by the current imaging modalities [16]. On the other hand, malformations that involve both the osseous and the membranous labyrinth are detectable by CT and MRI. Recognizable patterns of inner ear malformations were linked to the stage at which embryogenesis was hindered and could be classified into 2 main categories depending on the presence of an abnormal cochlea (category A) or a normal cochlea (category B) ( Table 1) [31, 32]. Cochlear malformations include complete labyrinthine (Michel) aplasia, cochlear aplasia, common cavity malformation, cochlear hypoplasia, and incomplete partition type I and II (Mondini) ( $\triangle$ Table 2, $\bullet$ Fig.3-5) [33]. Other anomalies include lateral semicircular canal and vestibule aplasia or dysplasia, enlarged vestibular aqueduct and cochlear nerve deficiency [31] ( $\bullet$ Fig. 6 ). Newer classifications also include the malformation of X-linked deafness and special aspects of the charge syndrome with a hypoplastic cochlea and absent semicircular causes.

Rarely complex malformations of the inner auditory canal need to be described. Also the risks of gusher in combination with special inner ear malformations, especially X-linked deafness, IPT1 and common cavity as well as otocystic deformities, have to be considered.

In the past, children with CT or MRI evidence of inner ear malformations were considered poor candidates for $\mathrm{CI}$, mainly because of concerns regarding the safety and feasibility of the procedure as well as the outcome. More recently, the advances in CT technology and surgical experience resulted in several reports of successful implantation in a variety of inner ear malformations or even in rare cases or tumors, facial or vestibular schwannomas or endolymphatic sac tumor ( $\bullet$ Fig. 7). There are also recommendations for using CT to avoid the expected surgical challenges such as cerebrospinal fluid gusher, facial nerve injury, and incomplete electrode insertion. The functional outcome, however, may vary according to the severity of the malformation. For example, children with milder forms like isolated enlarged vestibular aqueduct or Mondini malformation or partial semicircular canal dysplasia are reported to perform well, while poor outcome was reported in the presence of severe cochlear anomalies such as common cavity, cochlear hypoplasia, stenotic internal auditory canal, cochlear nerve deficiency, and complete aplasia of the semicircular canal $[34,35]$.
Table 1 Classification of congenital inner ear malformations according to Jackler et al. [32].

category A: aplasia or malformations of cochlea
1. Michel aplasia (labyrinthine aplasia)
2. cochlear aplasia, vestibule and semicircular canals present
3. cochlear hypoplasia
4. incomplete cochlea
5. common cavity
category B: normal cochlea
1. dysplasia of the vestibule and lateral semicircular canal
2. large vestibular aqueduct

Table 2 Main groups and configurations of inner ear malformations according to Sennaroglu et al. [28].

\begin{tabular}{|c|c|}
\hline main groups & configuration \\
\hline cochlear malformations & $\begin{array}{l}\text { michel aplasia/cochlear aplasia/ } \\
\text { common cavity/ incomplete parti- } \\
\text { tion type I/cochlear hypoplasia/ } \\
\text { incomplete partition type II/ } \\
\text { normal }\end{array}$ \\
\hline vestibular malformations & $\begin{array}{l}\text { vestibule: absent/hypoplastic/di- } \\
\text { lated (including Michel deformity } \\
\text { and common cavity) }\end{array}$ \\
\hline semicircular canal malformations & absent/hypoplastic/enlarged \\
\hline $\begin{array}{l}\text { internal auditory canal malfor- } \\
\text { mations }\end{array}$ & absent/narrow/enlarged \\
\hline $\begin{array}{l}\text { vestibular and cochlear aqueduct } \\
\text { malformations }\end{array}$ & enlarged/normal \\
\hline
\end{tabular}

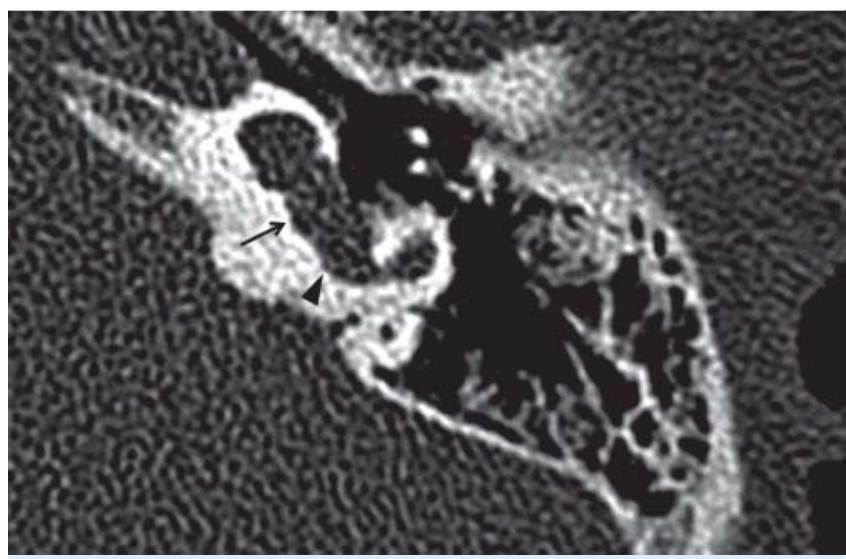

Fig. 3 Cystic cochleovestibular malformation with incomplete partition type I (IP-I): Axial CT scan shows complete absence of cochlear modiolus and interscalar septum. Vestibular enlargement and dilatation of the horizontal SCC (black arrow, arrowhead). It shows the typical "figure 8" morphology.

Abb. 3 Zystische cochleovestibuläre Malformation mit inkompletter Partition Typ I (IP-I): Axiale CT-Aufnahme zeigt komplettes Fehlen des Modiolus cochleae und des interskalaren Septums. Vestibuläre Vergrößerung und Dilatation des horizontalen Bogenganges (schwarzer Pfeil, Pfeilspitze). Daraus resultiert eine typische Morphe, die an die „Zahl 8“ erinnert.

\section{Pre-Operative Prediction of Electrode Insertion Length} $\nabla$

Pre-operative measurement of cochlear duct length is performed at some centers and may help in choosing the optimum length of the electrode array. In conventional implantation, the electrode 

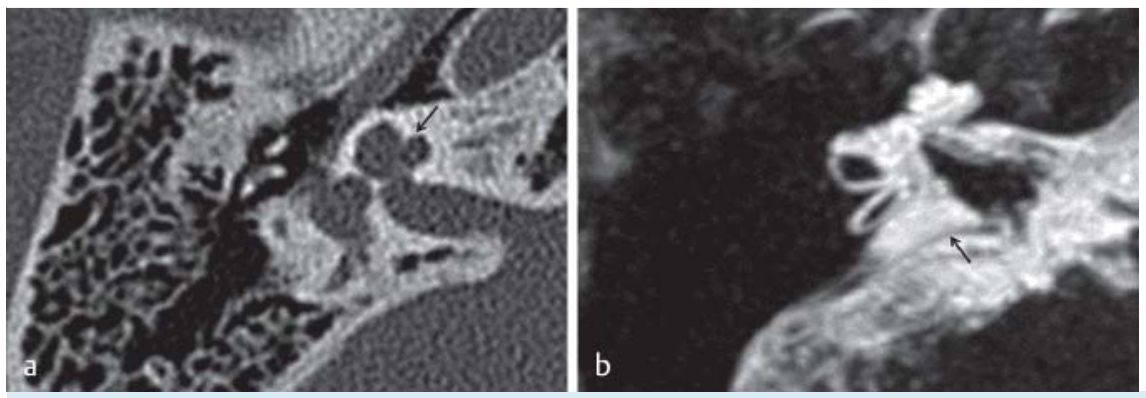

Fig. 4 Incomplete partition type II (IP-II). a Axial CT scan demonstrates plump middle and apical turns of the cochlea with smooth contour between the turns posterolaterally ("baseball cap" cochlea, arrow). b T2w MR MIP image shows Mondini anomaly: IP-II and LVDS= large vestibular duct and sac (black arrow).

Abb.4 Inkomplette Partition Typ II (IP-II). a Axiales CT zeigt plumpe mittlere und apikale Cochleawindungen mit glatter Kontur zwischen den posterolateralen Windungsanteilen („Baseball Cap“-Cochlea, schwarzer Pfeil). b T2-gewichtete MRT-MIP zeigt eine Mondini-Anomalie: IP-II und LVDS = large vestibular duct and sac (schwarzer Pfeil).
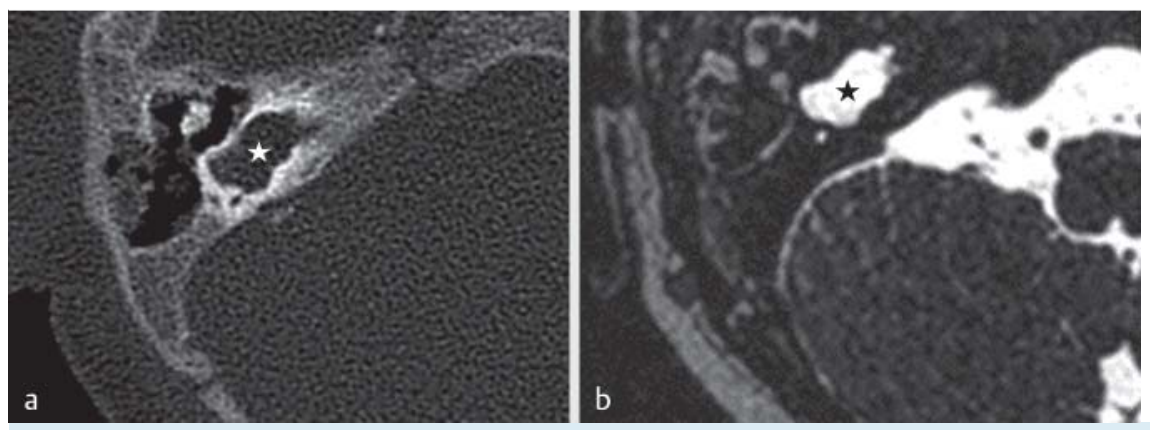

Fig. 5 "Common cavity". a 2-year-old boy with common cavity malformation. CT bone scan shows cochlea and vestibule melded into one common cyst (asterisk). b Axial 3D SPACE MR image demonstrates common fluid-filled cavity anomaly representing rudimentary cochlea, vestibule and horizontal semicircular canal (black asterisk).
Abb.5 „Common Cavity“. a 2-jähriger Junge mit „Common Cavity“-Malformation. CT-Knochenscan zeigt Cochlea und Vestibulum in einer gemeinsamen Zyste verschmolzen (Stern). b Axiale 3D-SPACE-MR-Tomografie zeigt gemeinsame flüssigkeitsgefüllte Höhlen-Anomalie mit rudimentärer Cochlea, Vestibulum und horizontalen knöchernem Bogengang (schwarzer Stern).
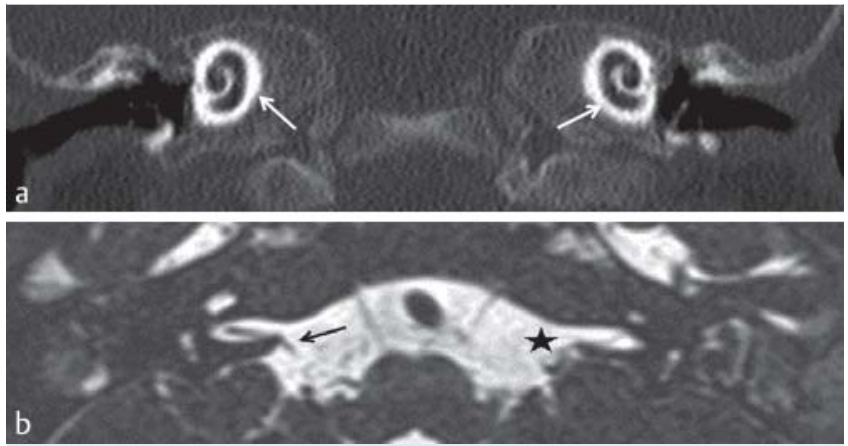

Fig. 6 Bilateral aplasia of the vestibulocochlear nerve and labyrinthine malformation in a 1-year-old boy. a Coronal CT multiplanar reconstruction shows normal appearance of the right cochlea (white arrows). $\mathbf{b}$ In 3D SPACE, the MR image shows an absence of the vestibulocochlear nerve on both sides. The right facial nerve appears normal (black arrow). The left facial nerve seems to be hypoplastic (black asterisk).

Abb. 6 Bilaterale Aplasie des Nervus vestibulocochlearis und Labyrinthmalformation bei einem 1-jährigen Jungen. a Koronale CT multiplanare Rekonstruktion zeigt eine regelrechte Darstellung der rechten Cochlea (weiße Pfeile). b Im 3D-Space-MRT Bild fehlt der Nervus vestibulocochlearis beidseits, der rechte Nervus facialis erscheint regelhaft (schwarzer Pfeil). Der linke Nervus facialis erscheint hypoplastisch (schwarzer Stern). array should be placed as deeply as possible into the scala tympani of the cochlea to stimulate the apically located neural structures [36]. On the other hand, in candidates of combined electric acoustic stimulation, residual hearing should be preserved by minimizing apical cochlear damage through limited insertion of the electrode. In such cases, pre-operative measurement of the cochlear length is an important factor in predicting the desired electrode insertion depth for successfully combined electricacoustic stimulation [37, 38].

CT is the method of choice for this purpose. One method used multi-planar reconstructions from spiral multi-detector CT acquisition, and the plane was adjusted until the optimal view of the basal turn of the cochlea was obtained. 25 to 30 reference points were set manually inside the cochlea. The software then provided measurement between the first point (round window membrane) and the last $360^{\circ}$ point [34]. Another method to predict the required insertion depth used a double coronal reformatted image from CT or MRI to obtain the "cochlear distance", which is the distance between the round window and the opposite wall of the cochlear basal turn. This distance was applied to a spiral function equation to calculate the required electrode length extending between the round window and the $360^{\circ}$ point and complete turn, which is the current technique for combined electric-acoustic stimulation $[37,38]$. 

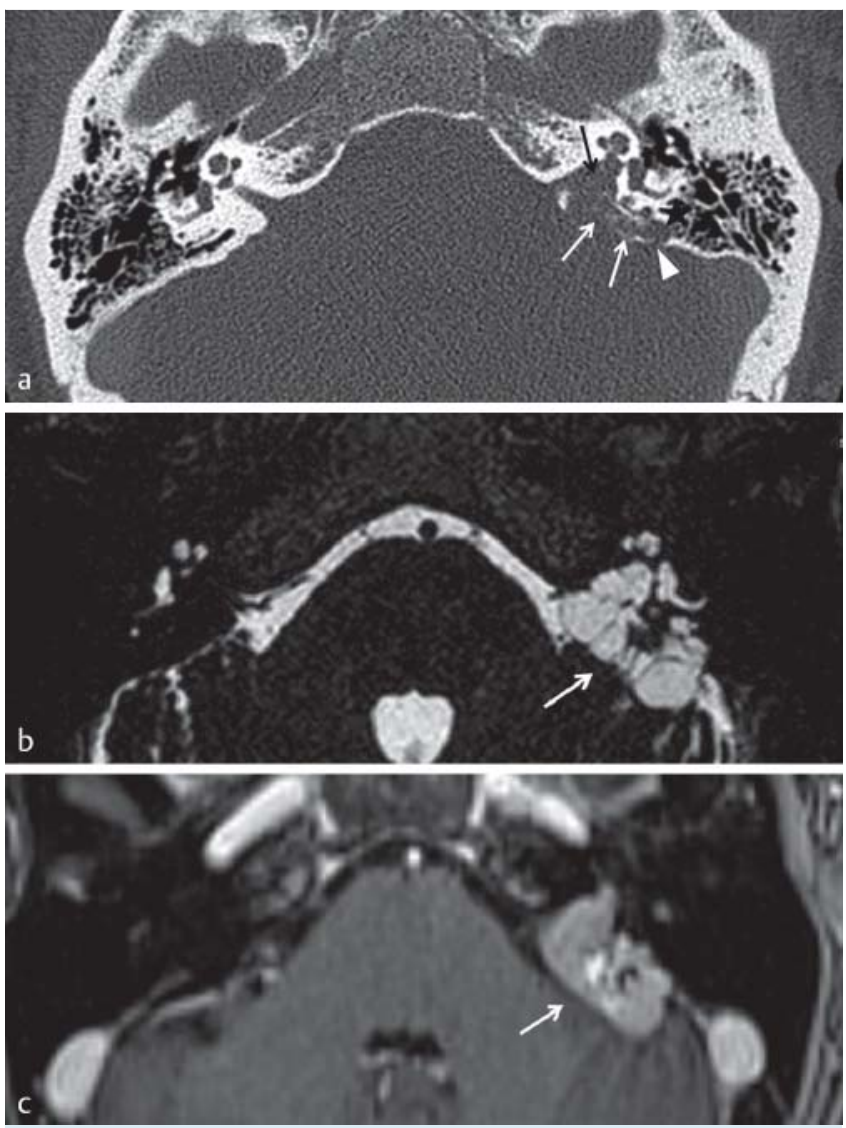

Fig. 7 Axial CT and MR images illustrate the typical appearance of an ELST (endolympathic sac tumor). a Transverse bone CT shows a speculated tumor matrix with permeative bone changes (white arrows) centered in the posterior T-bone area of the fovea of endolymphatic sac (white arrowhead), extending to IAC (black arrow) and mastoid (black asterisk). b Transverse T2w MR shows inhomogeneous generally hyperintense tumor (white arrow). c T1w MR after contrast medium application presents an intense heterogeneous enhancing mass (white arrow).

Abb. 7 Axiale CT- und MRT-Aufnahmen zeigen typisches Erscheinungsbild von ELST (Endolymphatischer Sack-Tumor). a Transversales KnochenCT zeigt Tumormatrix mit permeativen Knochenveränderungen (weiße Pfeile), zentriert im posterioren T-Bone-Bereich der Fovea des endolymphatischen Sacks (weiße Pfeilspitze), bis hin zum IAC (schwarzer Pfeil) und Mastoid (schwarzer Stern). b Transversale T2-gewichtete MR-Tomografie zeigt inhomogenen, allgemein hyperintensen Tumor (weißer Pfeil). c T1-gewichtete MR-Tomografie nach Kontrastmittelapplikation zeigt heterogene kontrastangereicherte Raumforderung (weißer Pfeil).

\section{Intra-Operative Imaging}

$\nabla$

For a long time intra-operative plain radiography was considered the method of choice for confirmation of the proper position of the CI, before surgery was concluded. Radiography is simple, inexpensive and reliable. A modified Stenver's view is usually obtained $[14,39]$. This enables prompt reinsertion in case of a misplaced electrode. Kinking of the electrode is characterized by abrupt angulation of its normally smooth contour. Intra-operative radiography also provides a baseline reference for further follow-up radiographs. C-arm fluoroscopy has replaced conventional portable radiography in most institutions. Rotational Carm fluoroscopy can provide $3 \mathrm{D}$ radiographs during operation after insertion of the electrodes, thus providing increased cer- tainty of correct positioning and enabling repositioning with low dose and little increase in operation time [40].

Flat-panel CT is based on C-arm fluoroscopy systems equipped with flat detectors enabling volume CT-like acquisitions. Those systems are increasingly used in guiding interventional procedures and in intra-operative imaging [24].

Conventional multi-detector CT scanners with wide bores were also recently used for intra-operative guidance of $\mathrm{CI}$ insertion in difficult cases with cochleovestibular anomalies and an abnormal course of the facial nerve $[41,42]$. Intra-operative CT can help to delineate important and necessary landmarks, such as the facial nerve, cochlea and intracochlear structures in real time during operation. In addition it can guide correct electrode placement. The field of intra-operative imaging continues to grow very fast and image-guided navigation systems for minimally invasive $\mathrm{CI}$ surgery as well as image-guided robotic surgery for direct cochlear access are currently under investigation [43-45].

\section{Post-Operative Imaging}

$\nabla$

The aim of post-operative imaging is to confirm intra-cochlear positioning of the electrode, detection of electrode kinking and assessment of electrode integrity. Until recently, plain radiography was the most commonly used post-operative imaging method ( $\odot$ Fig. 8a) [46]. Radiography is thus the method of choice in children [14].

Advances in electrode design with introduction of "modiolushugging" electrodes designed to be in a perimodiolar position rather than lying along the outer wall of the cochlea have initiated an interest in precise localization of the electrode position in relation to cochlear structures for accurately determining its insertion depth into the cochlea [47]. Further research for techniques providing precise post-operative localization focused on the use of multi-detector CT and flat-panel CT $[47,48]$.

\section{Plain X-ray \\ $\nabla$}

Many authors recommend only radiography and reserve CT for post-operative assessment of children with congenital malformations or in the presence of complications or when radiographs are abnormal or inadequate [14]. The most commonly used technique for post-operative radiographic assessment of $\mathrm{CI}$ is the Stenver's view with or without modification $[49,50]$. This view is performed with the patient standing facing a vertical bucky, with neck flexed so that the orbito-meatal line is perpendicular to the table and then the head is rotated so that the mid-sagittal plane is approximately $45^{\circ}$ to the film plane. The X-ray tube is angled in a way that the beam is approximately $12^{\circ}$ cephalad to the orbito-meatal line [46].

Several other radiograhic techniques and modifications were suggested as alternatives for the Stenver's view including the "cochlear view" [51], and direct anteroposterior view [52].

\section{Computed Tomography}

$\nabla$

However, current multi-detector CT scanners have enough spatial resolution to visualize each individual electrode contact and to avoid partial volume averaging and metallic artifacts [53-55]. 
In addition, software, multi-planar and volume-rendering techniques have significantly improved so that CT now plays a major role in post-operative evaluation of $\mathrm{CI}$ and offers unmatched imaging information $[56,57]$.

Currently CT is used to evaluate the effect of anatomical and surgical factors on results of speech perception after $\mathrm{CI}$, and to assess new technical innovations in electrode designs. In addition to the confirmation of intra-cochlear position, and the detection of mal-positioning and kinking of the electrode, post-operative CT currently aims at determining the exact position of individual electrode contacts, as well as the evaluation of the morphologic details of the cochlea and postoperative complications like infections $[55,58,59]$ ( $\bullet$ Fig. 8b).

Although flat-panel detector CT and cone beam CT scanners improve spatial resolution and decrease the radiation dose $[48,60$, 61 ], their availability is currently lower than that of conventional multi-detector CT.

\section{Electrode Misplacement \\ $\nabla$}

Misplacement of the $\mathrm{CI}$ electrode is a major complication of CI. CT is currently the method of choice for diagnosis and management planning ( $\bullet$ Fig.8c-d). Electrode misplacement can result in poor outcome and carries the risk of injury to important adjacent structures. Although misplacement was reported rarely in the literature, the true incidence is unknown. Reported sites of severe electrode misplacement detected by $\mathrm{CT}$ include the superior and horizontal semicircular canals, the vestibule, the Eustachian tube, the internal carotid artery, or the internal auditory canal [62].

\section{Magnetic Resonance Imaging \\ $\nabla$}

Cochlear implants have been considered an absolute contraindication for MRI [63]. The sources of incompatibility include excessive heating due to induced currents in the metallic components of the $\mathrm{CI}$, linear and torsional forces, demagnetization with loss of coupling between external and internal components and electronic malfunction $[63,64]$. As the number of patients with $\mathrm{CI}$ is continuously increasing, research by different research teams and manufacturers was directed towards exploring the MRI compatibility of different CI devices. Studies were performed in vitro first, and on scanners with a weak magnetic field, then on cadavers and volunteers using higher fields [64-66]. In the last decade, several authors have reported that patients with $\mathrm{CI}$ were safely imaged by MRI, if strict precautions are followed [64, 67]. Currently, most manufacturers of $\mathrm{CI}$ allow up to $1.5 \mathrm{~T}$ MRI scanning in patients with $\mathrm{CI}$ only under certain conditions. Guidelines include the removal of external components and the bandage covering the internal components, together with precautions about head positioning within the magnet bore [68]. Some manufacturers, however, still recommend removal of the internal magnet before MRI scanning [68]. It should be emphasized that before MRI scanning of a patient with $\mathrm{CI}$, the indication and risks must be discussed between the referring physician, the $\mathrm{CI}$ team and the radiology staff. Artifacts will also regularly limit the diagnostic quality of MR imaging whenever a $\mathrm{CI}$ is in place even without a magnet. Risks and benefits should be explained to the patient [69]. Currently there is still no evidence of the safety of $3 \mathrm{~T}$ MRI scanning in patients with a $\mathrm{CI}[70,71]$.

\section{Summary Statement}

$\nabla$

Imaging plays a major role in the preinterventional phase in candidates for a cochlear implant. Mostly complementary imaging of contrast-enhanced MRI and unenhanced CT, DVT, or cone beam $\mathrm{CT}$ is recommended. Intra-operative imaging is increasingly demanded and needs a well-balanced concept for imaging.

\section{References}

1 Lenarz T, Laszig R. Cochlea-Implantat Versorgung und zentral-auditorische Implantate. Leitlinie der Deutschen Gesellschaft für Hals-NasenOhren-Heilkunde, Kopf- und Hals-Chirurgie e.V., Bonn. Register number 017-071. http://www.awmf.org/leitlinien/detail/1//017-071.html Autorisiert für elektronische Publikation: AWMF online. May 2012. Accessed on line 18 April 2014.

2 Witte RJ, Lane JI, Driscoll CL et al. Pediatric and adult cochlear implantation. Radiographics 2003; 23: 1185 - 1200
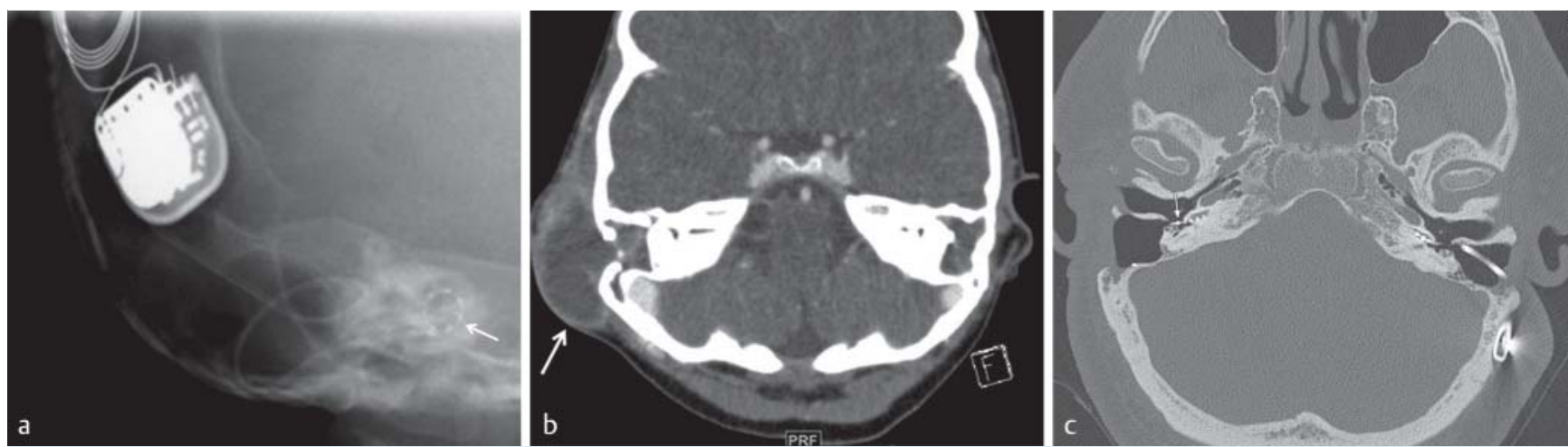

Fig. 8 Postoperative imaging. a Modified Stenvers view of the right temporal bone in a 5-year-old girl after bilateral $\mathrm{Cl}$. The X-ray demonstrates normal configuration of the distal cochlear implant wire spiraling within the cochlea (white arrow). The external $\mathrm{Cl}$ aggregate is partially shown. $\mathbf{b} 8$ days after $\mathrm{Cl}$ in the same patient: the contrast-enhanced CT scan demonstrates an abscess adjacent to the right mastoidectomy cavity (white arrow). c Axial CT scan demonstrates dislocation of the right electrode array (white arrow) after bilateral $\mathrm{Cl}$.
Abb. 8 Postoperative Bildgebung. a Modifizierte Röntgen-Stenvers Ansicht des rechten Schläfenbeins eines 5jährigen Mädchens nach bilateraler $\mathrm{Cl}$. Das Röntgenbild zeigt eine normale Konfiguration der distalen Cl-Elektrode innerhalb der Cochlea (weißer Pfeil). Zum Teil mitabgebildet sind externe Cl-Aggregatanteile. b 8 Tage nach $\mathrm{Cl}$ bei der gleichen Patientin: Ein kontrastmittelunterstützter CT-Scan zeigt einen Abszess benachbart zu der Mastoidektomie-Höhle (weißer Pfeil). c Axiales Knochen-CT-Scan zeigt eine $\mathrm{Cl}$-Elektrodendislokation rechts (weißer Pfeil) nach bilateraler $\mathrm{Cl}$. 
3 Huang BY, Zdanski C, Castillo M. Pediatric sensorineural hearing loss, part 1: Practical aspects for neuroradiologists. AJNR Am J Neuroradiol 2012; 33: $211-217$

4 Morton CC, Nance WE. Newborn hearing screening: a silent revolution. N Engl J Med 2006; 354: 2151 - 2164

5 Cureoglu S, Baylen MY, Paparella MM. Cochlear Otosclerosis. Curr Opin Otolarnygol Head Neck Surg 2010; 18: 357 - 362

6 Huang BY, Zdanski C, Castillo M. Pediatric sensorineural hearing loss, part 2: syndromic and acquired causes. AJNR Am J Neuroradiol 2012; 33: 399-406

7 Sampaio AL, Araujo MF, Oliveira CA. New criteria of indication and selection of patients to cochlear implant. Int J Otolaryngol 2011: 573968

8 Richard C, Fayad JN, Doherty J et al. Round window versus cochleostomy technique in cochlear implantation: histologic findings. Otol Neurotol 2012; 33: $1181-1187$

9 Kang BJ, Kim AH. Comparison of cochlear implant performance after round window electrode insertion compared with traditional cochleostomy. Otolaryngol Head Neck Surg 2013; 148: 822 - 826

10 Kronenberg J, Migirov L, Dagan T. Suprameatal approach: new surgical approach for cochlear implantation. J Laryngol Otol 2001; 115: $283-285$

11 Postelmans JT, Tange RA, Stokroos RJ et al. The suprameatal approach: a safe alternative surgical technique for cochlear implantation. Otol Neurotol 2010; 31: 196-203

12 Jeong SW, Kim LS. Cochlear implantation in children with cochlear aplasia. Acta Otolaryngol 2012; 132: $910-915$

13 Kontorinis G, Goetz F, Giourgas A et al. Aplasia of the cochlea: radiologic assessment and options for hearing rehabilitation. Otol Neurotol 2013; 34: $1253-1260$

14 Aschendorff $A$. Imaging in cochlear implant patients. Laryngorhinootologie 2011; 90: S16-S21

15 Trimble K, Blaser S, James AL et al. Computed tomography and/or magnetic resonance imaging before pediatric cochlear implantation? Developing an investigative strategy. Otol Neurotol 2007; 28: 317 - 324

16 Joshi VM, Navlekar SK, Kishore GR et al. CT and MR imaging of the inner ear and brain in children with congenital sensorineural hearing loss. Radiographics 2012; 32: 683-698

17 Giesemann AM, Raab P, Lyutenski S et al. Improved imaging of cochlear nerve hypoplasia using a 3-Tesla variable flip-angle turbo spin-echo sequence and a 7-cm surface coil. Laryngoscope; 2014; 124: 751 - 754

18 Huang BY, Roche JP, Buchman CA et al. Brain stem and inner ear abnormalities in children with auditory neuropathy spectrum disorder and cochlear nerve deficiency. AJNR Am J Neuroradiol 2010; 31: 1972 - 1979

19 Jäger L, Bonell H, Liebl M et al. CT of the normal temporal bone: comparison of multi- and single-detector row CT. Radiology 2005; 235: 133 141

20 Lane JI, Lindell EP, Witte RJ et al. Middle and inner ear: improved depiction with multiplanar reconstruction of volumetric CT data. Radiographics 2006; 26: 115-124

21 Jeon EJ, Jun B, Song JN et al. Surgical and radiologic anatomy of a cochleostomy produced via posterior tympanotomy for cochlear implantation based on three-dimensional reconstructed temporal bone CT images. Surg Radiol Anat 2013; 35: $471-475$

22 Schwab SA, Eberle S, Adamietz B et al. Comparison of 128-section single-shottechniquewithconventionalspiralmultisectionCTforimagingof the temporal bone. AJNR Am J Neuroradiol 2012; 33: 55-60

23 Kalender WA, Kyriakou Y. Flat-detector computed tomography (FDCT). Eur Radiol 2007; 17: 2767 - 2779

24 Gupta R, Bartling SH, Basu SK et al. Experimental flat-panel high-spatial resolution volume CT of the temporal bone. AJNR Am J Neuroradiol 2004; 25: $1417-1424$

25 Miracle AC, Mukherji SK. Conebeam CT of the head and neck, part 1: physical principles. AJNR Am J Neuroradiol 2009; 30: 1088-1095

26 Neri E, Caramella D, Cosottini M et al. High-resolution magnetic resonance and volume rendering of the labyrinth. Eur Radiol 2000; 10: $114-118$

27 Lane JI, Ward H, Witte RJ et al. 3-T imaging of the cochlear nerve and labyrinth in cochlear-implant candidates: 3D fast recovery fast spinecho versus 3D constructive interference in the steady state techniques. AJNR Am J Neuroradiol 2004; 25: 618-622

28 Casselman JW, Kuhweide R, Deimling $M$ et al. Constructive interference in steady state-3DFT MR imaging of the inner ear and cerebellopontine angle. AJNR Am J Neuroradiol 1993; 14: 47 - 57
29 Glastonbury CM, Davidson HC, Harnsberger HR et al. Imaging findings of cochlear nerve deficiency. AJNR Am J Neuroradiol 2002; 23: $635-643$

30 Chaturvedi A, Mohan C, Mahajan SB et al. Imaging of cochlear implants. Ind J Radiol Imag 2006; 16: 385 - 392

31 Krombach GA, Honnef $D$, Westhofen $M$ et al. Imaging of congenital anomalies and acquired lesions of the inner ear. Eur Radiol 2008; 18: $319-330$

32 Jackler RK, Luxford WM, House WF. Congenital malformations of the inner ear: a classification based on embryogenesis. Laryngoscope 1987; 97: $2-14$

33 Sennaroglu L, Saatci I. A new classification for cochleovestibular malformations. Laryngoscope 2002; 112: 2230-2241

34 Buchman CA, Copeland BJ, Yu KK et al. Cochlear implantation in children with congenital inner ear malformations. Laryngoscope 2004; 114: $309-316$

35 Vincneti V, Bacciu A, Guida $M$ et al. Pediatric cochlear implantation: an update. Ital J Pediatr 2014; 40: 72

36 Adunka O, Unkelbach MH, Mack MG et al. Predicting basal cochlear length for electric-acoustic stimulation. Arch Otolaryngol Head Neck Surg 2005; 131: $488-492$

37 Escude B, James J, Deguine 0 et al. The size of the cochlea and predictions of insertion depth angles for cochlear implant electrodes. Audiol Neurootol 2006; 11: 27-33

38 Connor SE, Bell DJ, O'Gorman $R$ et al. CT and MR imaging cochlear distance measurements may predict cochlear implant length required for a 360 degrees insertion. AJNR Am J Neuroradiol 2009; 30: 1425 - 1430

39 Cosetti MK, Troob SH, Latzman JM et al. An evidence-based algorithm for intraoperative monitoring during cochlear implantation. Otol Neurotol 2012; 33: 169-176

40 Carelsen B, Grolman W, Tange $R$ et al. Cochlear implant electrode array insertion monitoring with intra-operative 3D rotational X-ray. Clin Otolaryngol 2007; 32: $42-59$

41 Bloom JD, Rizzi MD, Germiller JA. Real-Time Intraoperative Computed Tomography to Assist Cochlear Implant Placement in the Malformed Inner Ear. Otol Neurotol 2009; 30: 23-26

42 Yuan YY, Song YS, Chai CM et al. Intraoperative CT-guided cochlear implantation in congenital ear deformity. Acta Otolaryngol 2012; 132 : 951-958

43 Majdani $\mathrm{O}$, Bartling SH, Leinung $M$ et al. Image-guided minimal-invasive cochlear implantation-experiments on cadavers. Laryngorhinootologie 2008; 87: $18-22$

44 Stelter K, Ledderose G, Hempel JM et al. Image guided navigation by intraoperative CT scan for cochlear implantation. Comput Aided Surg 2012; 17: 153 - 160

45 Bell B, Gerber N, Williamson T et al. In vitro accuracy evaluation of image-guided robot system for direct cochlear access. Otol Neurotol 2013; 34: $1284-1290$

46 Lawson JT, Cranley K, Toner JG. Digital imaging: a valuable technique for the postoperative assessment of cochlear implantation. Eur Radiol 1998; 8: 951 - 954

47 Verbist BM, Frijns JH, Geleijns J et al. Multisection CT as a valuable tool in the postoperative assessment of cochlear implant patients. AJNR Am J Neuroradiol 2005; 26: 424-429

48 Arweiler-Harbeck D, Mönninghoff C, Greve J et al. Imaging of Electrode Position after Cochlear Implantation with Flat Panel CT. ISRN Otolaryngol 2012; 2012: 728205

49 Todd NW, Ball TI. Interobserver agreement of coiling of Med-El cochlear implant: plain X-ray studies. Otol Neurotol 2004; 25: $271-274$

50 Bettman $R H$, vanOlphen $A F$, Zonneveld FW et al. Electrode insertion depth in cochlear implantees estimated during surgery, on plain film radiographs and with electrode function testing. Eur Arch Otorhinolaryngol 2003; 260: 536-540

$51 \mathrm{Xu}$ J, Xu SA, Cohen LT et al. Cochlear view: postoperative radiography for cochlear implantation. Am J Otol 2000; 21: 49-56

52 Harris $R$, Pepper C, Dennis L et al. A practical, single-view alternative to Stenver's for plain radiographic unilateral and bilateral post-cochlear implant position check. Cochlear Implants Int 2011; 12: $53-56$

53 Shpizner BA, Holliday RA, Roland JT et al. Postoperative imaging of the multichannel cochlear implant. AJNR Am J Neuroradiol 1995; 16 : $1517-1524$

54 Whiting BR, Bae KT, Skinner MW. Cochlear implants: three-dimensional localization by means of coregistration of $\mathrm{CT}$ and conventional radiographs. Radiology 2001; 221: $543-549$ 
55 Verbist BM, Joemai RM, Teeuwisse WM et al. Evaluation of 4 multisection CT systems in postoperative imaging of a cochlear implant: a human cadaver and phantom study. AJNR Am J Neuroradiol 2008; 29: $1382-1388$

56 Whiting BR, Holden TA, Brunsden BS et al. Use of computed tomography scans for cochlear implants. J Digit Imaging 2008; 21: 323 - 328

57 Kong WJ, Cheng HM, Ma H et al. Evaluation of the implanted cochlear implant electrode by CT scanning with three-dimensional reconstruction. Acta Otolaryngol 2012; 132: $116-122$

58 Finley CC, Holden TA, Holden LK et al. Role of electrode placement as a contributor to variability in cochlear implant outcomes. Otol Neurotol 2008; 29: $920-928$

59 Long CJ, Holden TA, McClelland GH et al. Examining the electro-neural interface of cochlear implant users using psychophysics, CT scans, and speech understanding. J Assoc Res Otolaryngol 2014; 15: 293 - 304

60 Ruivo J, Mermuys K, Bacher K et al. Cone beam computed tomography, a low-dose imaging technique in the postoperative assessment of cochlear implantation. Otol Neurotol 2009; 30: 299-303

61 Marx M, Risi F, Escudé B et al. Reliability of cone beam computed tomography in scalar localization of the electrode array: a radio histological study. Eur Arch Otorhinolaryngol 2014; 271: 673-679

62 Ying YL, Lin JW, Oghalai JS et al. Cochlear implant electrode misplacement: incidence, evaluation, and management. Laryngoscope 2013 ; 123: $757-766$

63 Portnoy WM, Mattucci K. Cochlear implants as a contraindication to magnetic resonance imaging. Ann Otol Rhinol Laryngol 1991; 100: $195-197$
64 Dyer RK Jr, Nakmali D, Dormer KJ. Magnetic resonance imaging compatibility and safety of the SOUNDTEC Direct System. Laryngoscope 2006; 116: 1321 - 1333

65 Youssefzadeh S, Baumgartner W, Dorffner $R$ et al. MR compatibility of Med EL cochlear implants: clinical testing at $1.0 \mathrm{~T}$. J Comput Assist Tomogr 1998; 22: $346-350$

66 Baumgartner WD, Youssefzadeh S, Czerny C et al. Clinical utilization of magnetic resonance imaging for patients with cochlear implants. Wien Klin Wochenschr 2000; 112: 512 - 514

67 Gubbels SP, McMenomey SO. Safety study of the Cochlear Nucleus 24 device with internal magnet in the 1.5 Tesla magnetic resonance imaging scanner. Laryngoscope 2006; 116: 865 -871

68 Dubrulle F, Vincent C, Varoquaux A et al. Guidelines for the performance of MRI in patients with cochlear implants. J Radiol 2011; 92: $872-877$

69 Broomfield SJ, Da Cruz M, Gibson WP. Cochlear implants and magnetic resonance scans: A case report and review. Cochlear Implants Int 2013; $14: 51-55$

70 Majdani 0 , Leinung $M$, Rau $T$ et al. Demagnetization of cochlear implants and temperature changes in 3.0 T MRI environment. Otolaryngol Head Neck Surg 2008; 139: 833 -839

71 Dubrulle F, Sufana Iancu A, Vincent $C$ et al. Cochlear implant with a non-removable magnet: preliminary research at 3-T MRI. Eur Radiol 2013; 23 : $1510-1518$ 